\title{
Factors Affecting Organisational Performance: A Case of a Human Settlement Department in South Africa
}

\author{
Zibasa Mabai, George Hove \\ Regent Business College, Durban, South Africa \\ Email: ghove20@telkomsa.net, zibasa29@gmail.com
}

How to cite this paper: Mabai, Z., \& Hove, G. (2020). Factors Affecting Organisational Performance: A Case of a Human Settlement Department in South Africa. Open Journal of Business and Management, 8, 2671-2686.

https://doi.org/10.4236/ojbm.2020.86165

Received: April 13, 2020

Accepted: November 20, 2020

Published: November 23, 2020

Copyright $\odot 2020$ by author(s) and Scientific Research Publishing Inc. This work is licensed under the Creative Commons Attribution International License (CC BY 4.0).

http://creativecommons.org/licenses/by/4.0/

\begin{abstract}
Organisations today are concerned about factors that affect their performance, including the role of strategic planning within the organisation as this enables the organisation to effectively and efficiently manage its resources. The purpose of this study was to determine the factors affecting the performance of the department of human settlements in South Africa (herein the department). The quantitative research method was used, and the study was piloted using six selected respondents from the targeted population of 89 and these respondents were excluded from the study. A questionnaire was designed to collect primary data, and 72 questionnaires were distributed to the randomly selected respondents and 45 responses were obtained representing a $65 \%$ response rate. The study established that environmental factors, working environment, organisational culture, organisational assets, human resources management, organisational structure and leadership are the factors that affect performance in the department. It was also established that strategic planning acts as a platform to align departmental strategic documents with government planning documents such as NDP and PDP, facilitate the setting of specific, measurable, achievable, realistic and time frame (SMART) objectives and targets, communicate departmental vision, values, goals and objectives effectively and clearly and provide feedback platform for planning outcomes and performance measurement. Based on the analysis undertaken, it was recommended that the department must strategically invest to improve the resources required to aid the employees to effectively execute their duties and that the department should ensure sufficient human resources to achieve the set strategic targets.
\end{abstract}

\section{Keywords}

Organisational Performance, Strategic Planning, Organisational Culture, Leadership 


\section{Introduction}

Over many decades, numerous studies have been conducted to explore the subject of organisational performance (Al-Tit, 2017). The studies identified many factors that have significant effects on organisational performance. For example, (Avdelidou-Fischer, 2006) investigated the relationship between organisational structure and the performance of fortune 500 companies. The result showed that structural types are positively related to financial performance. Felício, Couto, \& Caiado (2014) evaluated the human capital and social capital of managers and the influence of these attributes on the performance of small and medium-sized Portuguese companies. In this study, it was found that organisational performance is strongly influenced by human capital through the cognitive ability of the manager. Other factors identified in the literature include stakeholder involvement, CEO's social network, Perez, Morales, \& Sanchez (2012), organisational learning Morales, Reche, \& Torres (2008), human resources management, Ukanwah \& Ndaguba (2015) and organisational culture Yesil \& Kaya (2013).

Although many factors relating to organisational performance have been established in other parts of the world, there is lack of available literature and studies on this subject from South African context and this emphasizes the gap and necessity of this study. Specifically, the study was conducted to close this gap by assessing the factors that affect organisational performance at the Department of Human Settlement in the Eastern Cape Province. The department has a mandate to create long term sustainable human settlements and to improve the quality of household lives. However, departmental reports evaluated indicate that the performance of the department from 2012/13 financial year to 2016/17 has been a major concern among stakeholders. For example, the Auditor General reports raised issues relating to weak strategic planning and lack of information management systems among other factors (General Auditor Report 2016/17). In light of this, this paper seeks to assess the factors that affect organisational performance at the department. If the department is to fulfill its mandate, the authors have taken the corrective action to assist, as the recommendations would be provided to management for corrective action. The research question that guided this study was, "What are the factors affecting organisational performance at the department in South Africa?" The study has the following objectives:

- To assess the factors that affect the organisational performance of the department.

- To determine the role of strategic planning in the department.

- To establish the relationship between strategic planning and organisational performance.

This study is significant in what it can contribute to the body of knowledge on organisational performance. It is significant in what it has revealed about the factors affecting the department of human settlements and the recommendations assist management on how to deal with some of these factors in their quest 
to contribute meaningfully to the success of the department. It is also significant to stakeholders such as the government of South Africa that works closely with the department in highlighting the specific areas in which performance lacks. Most importantly, this paper raises awareness of the academic society that may result in the adjustment of performance management theories based on insights from this paper. However, as in any research project, there are limitations associated with the sampling of the population and data analysis. The results of this paper are based on the views of employees at the department of human settlement in South Africa and the factors established in this study are valid and can be applied to the department in South Africa. Therefore, these limitations should be kept in mind when interpreting the results of this study.

\section{Review of Literature}

In this section, a review of the literature regarding factors affecting organisational performance and the role of strategic planning on organisational performance was conducted.

\subsection{Strategic Planning and Performance}

As stipulated in National Treasury Framework (2007), all government departments are expected to formulate strategic plans, allocate resources to the implementation of those plans, and monitor and report the results through the strategic planning process and monitoring and evaluation thereof. For the departments to achieve this goal, issues of organisational performance and strategic planning become vital. By definition, an organisation's strategic planning efforts should guide the necessary activities that would lead to positive organisational performance. There is a stream of literature on organisational performance that suggests that the performance of the organisation is a measurement based on multivariate effective measures. Hove \& Banjo (2015) suggest that organisational performance is a subset of organisational effectiveness. On the other hand, strategic planning efforts should guide the necessary activities to adapt to the organisational environment to achieve the desired performance. Dobrin, Popescu, Popescu, \& Popescu (2012) defined performance in organisations as reaching the strategic objectives, the focus of this definition is on efficiency which is measured quantitatively. Gavrea, Ilieş, \& Stegerean (2011) emphasis on continuous performance and allude that this should be the focus of any organisation because only through performance organisations can grow and prosper.

\subsection{Factors Affecting Organisational Performance}

Based on the reviewed literature, several empirically based factors were noted, including stakeholder involvement, intellectual capital, human resource management, personal factors, age of employees and gender, organisational characteristics, creativity and innovation. Other factors mentioned in the literature include the organisational environment, corporate governance, innovation and 
development, supportive organisational climate and organisational structure. For example, a recent empirical study by Al-Tit (2017) on Jordan manufacturing firms found that cultural factors, values and beliefs had an impact on organisational performance. In another study by Dobrin, Popescu, Popescu, \& Popescu (2012), the importance of employee performance in Romanian business organisations was established. However, this study was narrowed down and considered the factors as classified below. The chosen factors were a result of the severity literature had reported them, and were based on empirical studies.

\subsubsection{Human Resources Management (HRM)}

The subject of human resources management has been widely covered in the literature. It deals with the management of the employees of an organisation and more specifically, putting the right people to the right task thereby making maximum use of the employees' talent and abilities. In a study conducted by Ukanwah \& Ndaguba (2015), it was found that the competitiveness of an organisation is dependent on its employees' ability to generate process and apply knowledge. This result is in line with practitioners of human resources management who regard a workforce that is properly trained and managed as a source of competitive advantage. The treatment of human resources in terms of motivation influences the way organisations perform. The attainment of strategic management goals depends on the degree to which the human resource function is handled (Yllmaz \& Bulut, 2015). It is, therefore, imperative that organisations manage human resource function effectively and efficiently to achieve the desired goals and objectives (Cania, 2014).

\subsubsection{Organisational Assets}

The assets of the organisation should be well maintained and managed so that employees have the required resources to perform their duties. Organisations without suitable assets to perform the work will negatively affect their planned goals and strategic objectives. According to Hastings (2010), the purpose of the asset management function is to provide resources and expertise to support the acquisition, in-service support and disposal of the physical assets required by the organisation. Recently, asset management systems have been implemented within the public sector to assist with the development and implementation of the asset management in local government.

\subsubsection{Organisational Culture}

Conducive organisational culture contributes significantly towards the factors that increase the organisational performance and that reflects the success or failure of the organisation especial in government where citizens believe that government employees are slothful and have unacceptable attitudes towards serving their customers. In an empirical study by Ahmed \& Shafiq (2014), it was found that knowledge of the organisation culture permits employees to understand the history and functioning of the organisation. It was further found that organisa- 
tional culture raises devotion to the organisation's philosophy and values and that organisational culture, with its norms, deal as a control mechanism to direct behaviours toward expected behaviours and away from unfavourable behaviours.

\subsubsection{Leadership}

Empirical evidence from literature points that success in an organisation in terms of the attainment of goals and realisation of objectives depends on managers and their leadership style (Mclaggan, Bezuidenhout, \& Botha, 2013). A study by Hurduzeu (2015) postulates that to increase organisational performance, a leader must have the ability to promote creativity and innovation, stimulate the subordinates to challenge their value systems and improve their performance. In another study by Randeree \& Chaudhry (2012), consultative and consensus leadership styles were found in the construction sector in the United Arab Emirates. The study established that an employee's job satisfaction is strongly affected by leadership, with more than 50 per cent of surveyed respondents stating that leadership strongly influences job satisfaction. Therefore, effective leadership is vital because the effectiveness of the leader determines the eventual success of the organisation (Mokgolo, Mokgolo, \& Modiba, 2012).

\subsubsection{Working Environment}

There is much evidence in the literature confirming that a conducive working environment can improve the performance of the employees while a non-conducive environment could create threats to employees. In an empirical study that examined multiple organisational climates and their relationship with politics and performance in public organisations by Vashdi, Vigoda-Gadot, \& Shlomi (2012), four types of climates (participative, innovative, leadership and service) were found to impact employees' performance and public service outcomes and that perception of organisational politics mediate these relationships. In another study by Tiawo \& Idunnu (2010), the work environment provides a platform for employees to share the knowledge throughout the organisation; however, the quality of comfort derivable from work environment determines the level of satisfaction and productivity of workers.

\subsubsection{Organisational Structure}

The organisational structure must be developed and be responsive to the achievement of organisational goals. From management literature, the organisational structure includes the nature of formalization, layers of hierarchy, level of horizontal integration, centralization of authority and patterns of communication. According to Maduenyi, Oke, Fadeyi, \& Ajagbe (2015), the purpose of organisational structure is the division of work among members of the organisation and the coordination of their activities so that they are directed towards the goals and objectives of the organisation. In a study conducted by the same authors, it was revealed that organisational structure has an impact on organisa- 
tional performance and this demonstrates that organisations should have well-defined structures in place to achieve set objectives. If the organisational structure is effective, this would facilitate working relations among sub-unit of the organisation and may improve the company efficiency within the organisational units.

\subsubsection{Environmental Factors}

Both internal and external environmental factors affect organisational performance, it is therefore imperative for an organisation to analyse its environment whether through the utilization of strengths, weaknesses, opportunities and threats (SWOT) analysis and political, economic, social, technological, environmental and legal (PESTEL) analysis. Business is influenced by the environment in which it operates and the success of any business is dependent on its ability to adapt to its environment (Chitechi, 2014). Chitechi (2014) further states that the changes in the external environment have a significant impact on the survival and success of the organisation. Environmental analysis is conducted to assess the level of threat or opportunity that the organisation should be aware of to influence the decision-making process.

\subsection{Strategic Planning Process}

Over the past decades or so, the concept of strategic planning has crept into the public sector and has been adopted as a technique for corporate planning. According to Arasa (2012), strategic planning is the process of selecting organisational goals and strategies, determining the necessary programs to achieve specific objectives en route to the goals, and establishing the methods necessary to ensure that the policies and programs are implemented. Kibachia, Iravo, \& Luvanda (2014) state that strategic planning processes are designed to fit the specific need of the organisation, however, the process should include the vision and mission, environmental analysis, setting objectives and strategic analysis choice. In line with Kibachia, Iravo, \& Luvanda (2014), Owolabi \& Makinde (2012) emphasized environmental analysis, resource analysis, determination of the extent to which strategy change is required decision making, implementation and control. The effectiveness of strategic planning is associated with the achievement of the formulated objectives and improvement of organisational performance and this is attributed to the strategic planning process Šuklev \& Debarliev (2012).

\section{Methodology}

The study was quantitative in nature. Eyisi (2016) explains that quantitative research involves the use of statistical data for the research descriptions and analysis reduces the time and effort which the researcher would have invested in describing his result. The researchers used quantitative design for easy analysis and presentation of data in numbers, statistics and table format. The approach was 
appropriate as the researcher intended to generalise the results, in line with Rahman (2016) who state that quantitative research findings can be generalised to a larger population as it involves the larger sample based on random selection.

\subsection{Sampling Strategy}

The target population of this study comprised of the employees in the department in the Eastern Cape department of human settlement in South Africa. The departmental database was used as the sampling frame and it was from the sampling frame that sampling units were selected using the simple random method. In line with Powell (1997), the population of this study was selected with great care bearing in mind the selection criteria, the desired size and the parameters of the survey. The sampling frame was checked and cleaned to ensure no duplications were recorded, employees who had left the department were removed and newly recruited employees were excluded as this would provide skewed results. This was done to ensure that the sampling frame was as representative as possible of the target population. The research population for this study comprised of 89 employees. Using a software sampling calculator (Figure 1), a sample size of 72 was considered representative.

\subsection{Development of the Instrument}

A close-ended or structured questionnaire with 24 item questions was developed on a 5 point Likert scale. The respondents had a choice of choosing from 1"strongly disagree", 2-“disagree", 3-“uncertain", 4-"agree" and 5-“strongly agree". The questionnaire comprised of three sections (A, B and C). Section A addressed the biographical characteristics of the respondents; section $B$ looked at the factors that affect organisational performance while section $C$ visited the role of strategic planning. A questionnaire with close-ended questions was chosen to provide easier and quicker answers for the respondents.

\subsection{Validity and Reliability}

The validity of the instrument was established by asking academics from the local university to comment on the relevance and adequacy of the questionnaire about the research objectives. Comments received were about wording and sequencing of the questions and these were corrected to the satisfaction of the academics. Further, the questionnaire was tested for internal consistency and reliability. Cronbach's Alpha value was calculated for the items on the scale (Table $1)$.

Table 1. Cronbach's Alpha coefficient.

\begin{tabular}{cc}
\multicolumn{2}{c}{ Reliability Statistics } \\
\hline Cronbach's Alpha & N of Items \\
.831 & 18 \\
\hline
\end{tabular}




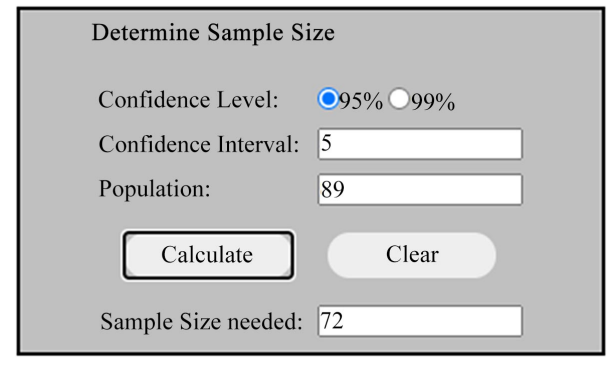

Figure 1. Sampling calculator. Source: https://www.surveysystem.com/sscalc.htm.

The overall reliability of Cronbach's alpha coefficient computed for this study was above the minimum recommended threshold of .70. Cronbach's alpha coefficient of .831 depicts a significantly high degree of reliability that could be placed on the questionnaire used to collect the data for the study.

\subsection{Data Analysis}

Data preparation was conducted and this was done to check the quality of data gathered during fieldwork and converted into the correct format for further analysis. This was achieved through validating, editing, coding, data entry and data cleaning. The analysis of data was done using SPSS version 25 . The results of the study were presented in the form of descriptive statistics and inferential statistics with tables used to represent the statistical results.

\section{Results}

A total of 72 questionnaires were distributed to randomly selected respondents. 52 questionnaires were received from the respondents and 20 were not returned. Of the 52 questionnaires returned, 45 were usable giving a response rate of $62 \%$. The response rate was acceptable as it was found to be higher than many response rates of the same type as reported in the literature. For example, Greenlaw \& Brown-Wetty (2009) achieved a response rate of 51.58\% which was acceptable in that study. The gender characteristics of the respondents were dominated by the female at $67 \%$, demonstrating that women have embraced the importance of education and acquisition of professional qualifications and this has put them in better positions for employment opportunities.

\subsection{Factors Affecting Organisational Performance}

An analysis of the factors affecting the organisational performance of the department was conducted and the results are illustrated in Table 2.

As depicted in Table 2, the views of the respondents are indicated by the overall mean of 48.378 and the corresponding standard deviation of 5.437. Amongst the factors affecting the performance of the department, the respondents statistically confirmed "economic factors" with a mean of 3.73 and a corresponding standard deviation of .751. This was followed by "government policies", 
Table 2. Factors affecting the organisational performance of the department.

\begin{tabular}{cccccc}
\hline Variable & N & Min & Max & Mean & Std. dev \\
\hline Human resources & 45 & 1 & 5 & 2.80 & .991 \\
Organisational Asset & 45 & 1 & 5 & 2.84 & 1.043 \\
Government policies & 45 & 2 & 5 & 3.56 & .725 \\
Organisational culture & 45 & 1 & 5 & 3.11 & 1.049 \\
Leadership & 45 & 1 & 4 & 2.38 & .806 \\
Working environment & 45 & 1 & 5 & 3.40 & 1.095 \\
Organisational structure & 45 & 1 & 4 & 2.56 & .867 \\
Economic factors & 45 & 2 & 5 & 3.73 & .751 \\
Technology & 45 & 1 & 4 & 2.71 & .944 \\
Factors that affect Organisational Performance Average & 45 & 37.00 & 60.00 & 48.378 & 5.437 \\
Valid N (listwise) & 45 & & & & \\
\hline
\end{tabular}

rated with a mean of 3.56 and the corresponding standard deviation of .725. The third factor was "working environment", rated with a mean of 3.40 and the corresponding standard deviation of 1.095 . The fourth factor was: "organisational culture", rated with a mean of 3.11 and a corresponding standard deviation of 1.049. The fifth factor was "organisational assets", rated with a mean of 2.84 and the corresponding standard deviation of 1.034. This was followed by "human resources", rated with a mean of 2.80 and a corresponding standard deviation of .991. The "technology" factor was rated with a mean of 2.71 and a corresponding standard deviation of .944, "organisational structure", was rated with a mean of 2.56 with a corresponding standard deviation of .867. The least factor was "leadership", which had a mean of 2.38 with a corresponding standard deviation of .806 .

\subsection{The Role of Strategic Planning towards Organisational Performance}

The role of strategic planning was assessed and the results are reflected in the table in Table 3.

The results in the table show the role and process of strategic planning in the department. The acknowledgement of the role of strategic planning was statistically confirmed with a mean of 30.711 and a corresponding standard deviation of 3.835. Strategic planning in the department begins with a need to align the strategic plan with the broader national and provincial guiding policies, as indicated in the table above-"alignment of the departmental strategic plan", rated with a mean of 4.07 and a corresponding standard deviation of .654. The thorough knowledge and understating of the importance and role of planning in the department was demonstrated by the rating of "contribution of plans to overall 
performance", rated with a mean of 3.87 and a corresponding standard deviation of .588. This was followed by "communication of vision, values, goals and objectives", rated with a mean of 3.84 and corresponding standard deviation of .737. "the set SMART objectives", was rated with a mean of 3.47 and a corresponding standard deviation of .894 , which was followed by-"departmental management commitment", rated with a mean of 3.40 and a standard deviation of .889 . The "feedback on planning outcomes and performance measurement" was rated with a mean of 3.36 and a corresponding standard deviation of .933, the "use of previous year annual reports for future planning" was tested and it had a mean of 3.20 and a corresponding standard deviation of .726. The "situational analysis (SWOT)" had a mean of 2.87 and a standard deviation of .786. The "alignment of strategic planning documents", had a mean of 2.64 and a corresponding standard deviation of 1.228 .

Table 4 below presents the inferential statistics of correlation of the strategic planning role factors towards contribution to the organisational performance of the department.

The statistical results from the simple linear regression analysis in Table 4 indicate that strategic planning accounted for $56.2 \%\left(\mathrm{R}^{2}=.562\right)$ of the variance in the organisational performance of the department.

The statistical results in Table 5 indicate that the model is statistically significant $(\mathrm{F}=55.209$, Sig. $=.000)$, meaning that strategic planning significantly contributes to the organisational performance of the department.

Table 6 indicates the statistical results of the linear regression analysis that reflect a possible significant contributing role in strategic planning towards the organisational performance of the department $(t=7.430$, Sig. $=.000)$.

Table 3. The role of strategic planning.

\begin{tabular}{cccccc}
\hline Variable & N & Min & Max & Mean & Std. Dev \\
\hline Alignment of the departmental strategic plan & 45 & 3 & 5 & 4.07 & .654 \\
Communication of vision, values, and objectives & 45 & 1 & 5 & 3.84 & .737 \\
Contribution of plans to the overall performance & 45 & 3 & 5 & 3.87 & .588 \\
Departmental management commitment & 45 & 1 & 5 & 3.40 & .889 \\
Alignment of strategic planning documents & 45 & 1 & 5 & 2.64 & 1.228 \\
The set SMART objectives & 45 & 2 & 5 & 3.47 & .894 \\
Situational analysis (SWOT) & 45 & 1 & 5 & 2.87 & .786 \\
Use of annual reports for future planning & 45 & 2 & 4 & 3.20 & .726 \\
Feedback on planning outcomes and performance & 45 & 1 & 5 & 3.36 & .933 \\
The Role of Strategic Planning Average & 45 & 23.00 & 42.00 & 30.711 & 3.835
\end{tabular}


Table 4. Regression model summary.

\begin{tabular}{ccccc}
\hline \multicolumn{5}{c}{ Model Summary } \\
\hline Model & $\mathrm{R}$ & R Square & Adjusted R Square & Std. Error of the Estimate \\
\hline 1 & $.750^{\mathrm{a}}$ & .562 & .552 & 3.63908 \\
\hline
\end{tabular}

a. Predictors: (Constant), The Role of Strategic Planning.

Table 5. Analysis of variance (ANOVA).

\begin{tabular}{ccccccc}
\hline \multicolumn{7}{c}{ ANOVA } \\
\hline \multicolumn{1}{c}{ Model } & Sum of Squares & df & Mean Square & F & Sig. \\
\hline & Regression & 731.133 & 1 & 731.133 & 55.209 & $.000^{\text {b }}$ \\
1 & Residual & 569.445 & 43 & 13.243 & & \\
& Total & 1300.578 & 44 & & & \\
\hline
\end{tabular}

a. Dependent Variable: Organisational Performance; b. Predictors: (Constant), The Role of Strategic Planning.

Table 6. Coefficients.

\begin{tabular}{|c|c|c|c|c|c|c|}
\hline \multicolumn{7}{|c|}{ Coefficients } \\
\hline & \multirow{2}{*}{ Model } & \multicolumn{2}{|c|}{ Unstandardized Coefficients } & \multirow{2}{*}{$\begin{array}{c}\text { Standardized Coefficients } \\
\text { Beta }\end{array}$} & \multirow{2}{*}{$\mathrm{t}$} & \multirow{2}{*}{ Sig. } \\
\hline & & B & Std. Error & & & \\
\hline & (Constant) & 15.737 & 4.426 & & 3.555 & .001 \\
\hline 1 & $\begin{array}{c}\text { The Role of } \\
\text { Strategic Planning }\end{array}$ & 1.063 & .143 & .750 & 7.430 & .000 \\
\hline
\end{tabular}

a. Dependent Variable: Organisational Performance.

\section{Discussion}

\subsection{Factors That Affect Organisational Performance}

The results show that the department is negatively affected by economic factors as confirmed by the majority of the respondents. Changes in the government policies were positively confirmed and they assist the department to improve its performance. These findings are in line with Chitechi (2014) who argued that changes in the external environment have a significant impact on the survival and success of organisations. It was interesting to note that the organisational culture of the department was acknowledged as conducive for employees to perform well and contribute positively to the performance of the department, albeit the department operating under a highly politicised environment. This result concurs with Ahmed \& Shafiq (2014) who note that knowledge of the organisation culture permits employees to understand the history and functioning of the organisation.

Of concern rather, was a cautious and indifference disposition displayed by the respondents as evidenced by low average means and high standard devia- 
tions, regarding the adequate resourcing of the department. There was scepticism about organisational assets to enable the employees to execute their duties effectively, and also about the department having sufficient human resources to achieve its targets. At the same time, there was concern about the current organisational structure of the department and its ability to respond to the organisational needs. Use of technology as well, seemingly it was a cause for concern. Availability of state of art technology would naturally positively influence the performance of employees in organisations, while non-availability or non-use of technology would negatively influence or impact the performance of employees in organisations. It appears the department had the challenge in the use of technology. There was also scepticism on whether a change of leadership in the department resulted in highly motivated management and employees and improved organisational performance. These findings resonated well with Maduenyi, Oke, Fadeyi, \& Ajagbe (2015) and Mokgolo, Mokgolo, \& Modiba (2012) that organisational structure has an impact on organisational performance and this demonstrates that organisations should have well-defined structures in place to achieve set objectives and that the effective leadership is vital because the effectiveness of the leader determines the eventual success of the organisation.

\subsection{Importance of Strategic Planning towards Organisational Performance}

The results have shown that strategic planning provides a platform for the department to be able to align its departmental strategic plans. Concerning the 2014-2019 strategic plans, for example, the process of strategic planning provided a platform and vehicle for the department to ensure that the 2014-2019 strategic plans are aligned, with the clear understanding that departmental plans contribute towards the overall performance of the department. From the findings, it was established that there is a positive and significant correlation between the alignment of the department's strategic plan for the period 2014-2019 with the communication of the department's vision, values, goals and objectives.

To facilitate the desirable performance of the department, strategic planning processes aid the department to be able to communicate its departmental goals and objectives effectively and clearly to all employees of the department, and SMART objectives and targets are set during the strategic planning processes for the department. There is a positive and significant correlation between set SMART objectives and feedback on the planning outcomes and performance measurement. There is a clear management commitment in the department, to the strategic planning success and strategic direction, with proper feedback mechanisms put in place to disseminate the strategic planning outcomes. Also, there is a positive and significant correlation between set SMART objectives and feedback on planning outcomes and performance measurement. The results are in line with Kibachia, Iravo, \& Luvanda (2014), Šuklev \& Debarliev (2012) who confirmed that strategic process should include the vision and mission, envi- 
ronmental analysis, setting objectives and strategic analysis choice. Further, some authors agree that the effectiveness of strategic planning is associated with the achievement of organisational objectives and performance.

\section{Recommendations}

Based on the findings of this study, the following recommendations were made:

- The department must strategically invest to improve the resources required to aid the employees to effectively execute their duties.

- The department should ensure that there are sufficient human resources to achieve a set of strategic targets.

- The department must adopt and embrace the use of technology in the operations of the department as technology has the potential of positively affecting the performance of the employees.

- The department must re-visit its organisational structure and streamline it so that it can effectively and efficiently respond to organisational needs.

\section{Practical Implications}

The data from the study reveal that the department has a well-developed organisational culture that keeps employees motivated and committed towards achievement of organisational performance. While certain functions within the department require attention, there are some functions which should be commended. However, currently, there is much discourse about the performance of the department and this study has examined and identified the factors that affect the department's performance.

\section{Conclusion and Further Research Perspectives}

The study was set out to examine the factors affecting organisational performance at the department in South Africa. The study established that environmental factors, working environment, organisational culture, organisational assets, human resources management, organisational structure and leadership are the factors that affect performance in the department. Furthermore, it was established that strategic planning acts as a platform to align departmental strategic documents with government planning documents such as NDP and PDP, facilitate the setting of SMART objectives and targets, communicate departmental vision, values, goals and objectives effectively and clearly and provide feedback platform for planning outcomes and performance measurement.

\section{Further Research}

Several issues suitable for further researches have been raised in this study. This study was limited to one province of South Africa and future studies can be conducted to other departments of South Africa and its nearby African counties to validate findings reported in this paper. 


\section{Acknowledgements}

The authors would like to thank the management of the department for allowing ZM access to utilise their database for this study and all the employees for participating in the study and providing valuable inputs.

\section{Conflicts of Interest}

The authors declare no conflicts of interest regarding the publication of this paper.

\section{References}

Ahmed, M., \& Shafiq, S. (2014). The Impact of Organisational Culture on Organisational Performance: A Case Study of the Telecom Sector. Global Journal of Management and Business Research: Administration and Management, 14, 21-30.

Al-Tit, A. A. (2017). Factors Affecting the Organisational Performance of Manufacturing Firms. International Journal of Engineering Business Management, 9, 1-9. https://doi.org/10.1177/1847979017712628

Arasa, R. (2012). The Relationship between Strategic Planning and Firm Performance. International Journal of Humanities and Social Science, 2, 201-213.

Avdelidou-Fischer, N. A. (2006). The Relationship between Organisational Structures and Performance: The Case of the Fortune 500. In J. J. Choi, \& R. W. Click (Eds.), Value Creation in Multinational Enterprise (International Finance Review, Volume 7) (pp. 169-206). Bingley: Emerald Group Publishing Limited. https://doi.org/10.1016/S1569-3767(06)07008-7

Cania, L. (2014). The Impact of Strategic Human Resource Management on Organisational Performance. Economia. Seria Management, 17, 373-383.

Chitechi, W. E. (2014). Research Project on External Environmental Factors Affecting the Performance of the Export of Services Sector in Kenya.

Dobrin, C. O., Popescu, G. N., Popescu, V. A., \& Popescu, C. R. (2012). The Concept of Performance in Business Organisations-Case Study on the Employee Performance in Romanian Business Organisations. Proceedings of the International Management Conference, Faculty of Management, Academy of Economic Studies, Bucharest, Romania, 6, 310-316.

Eyisi, D. (2016). The Usefulness of Qualitative and Quantitative Approaches and Methods in Researching Problem-Solving Ability in Science Education Curriculum. Journal of Education and Practice, 7, 91-100.

Felício, J. A., Couto, E., \& Caiado, J. (2014). Human Capital, Social Capital and Organisational Performance. Management Decision, 52, 350-364.

https://doi.org/10.1108/MD-04-2013-0260

Gavrea, C., Ilieş, L., \& Stegerean, R. (2011). Determinants of Organisational Performance: The Case of Romania. Management \& Marketing Challenges for the Knowledge Society, 6, 285-300.

Hastings, N. A. J. (2010). Physical Asset Management. Berlin: Springer. https://doi.org/10.1007/978-1-84882-751-6

Hove, G., \& Banjo, A. (2015). Performance in the Construction Industry-A Conceptual and Theoretical Analysis. Open Journal of Business and Management, 3, 177-184. https://doi.org/10.4236/ojbm.2015.32017 
Hurduzeu, R. E. (2015). The Impact of Leadership on Organisational Performance. SEA Practical Application of Science, 3, 289-294.

Kibachia, J., Iravo, M., \& Luvanda, A. (2014). A Survey of Risk Factors in the Strategic Planning Process of Parastatals in Kenya. European Journal of Business and Innovation Research, 2, 51-67.

Maduenyi, S., Oke, A. O., Fadeyi, O., \& Ajagbe, M. A. (2015). Impact of Organisational Structure on Organisational Performance. International Conference on African Development Issues 2015: Social and Economic Models for Development Track.

Mclaggan, E., Bezuidenhout, A., \& Botha, C. T. (2013). Leadership Style and Organisational Commitment in the Mining Industry in Mpumalanga. South African Journal of Human Resource Management, 11, 1-9. https://doi.org/10.4102/sajhrm.v11i1.483

Mokgolo, M. M., Mokgolo, P., \& Modiba, M. (2012). Transformational Leadership in the South African Public Service after the April 2009 National Elections. South African Journal of Human Resource Management, 10, 1-9. https://doi.org/10.4102/sajhrm.v10i1.334

Morales, V. J. G., Reche, F. M., \& Torres, N. H. (2008). Influence of Transformational Leadership on Organisational Innovation and Performance Depending on the Level of Organisational Learning in the Pharmaceutical Sector. Journal of Organisational Change Management, 21, 188-212. https://doi.org/10.1108/09534810810856435

National Treasury Framework (2007).

Owolabi, S. A., \& Makinde, O. C. (2012). The Effects of Strategic Planning on Corporate Performance in University Education: A Study of Babcock University. Kuwait Chapter of Arabian Journal of Business and Management Review, 2, 27-44.

Perez, V. F., Morales, V. J. C., \& Sanchez, O. F. B. (2012). The Effects of CEOs' Social Networks on Organisational Performance through Knowledge and Strategic Flexibility. Personnel Review, 41, 777-812. https://doi.org/10.1108/00483481211263719

Powell, R. R. (1997). Basic Research Methods for Librarians (3rd ed.). Westport, CT, London: Ablex Publishing.

Rahman, M. S. (2016). The Advantages and Disadvantages of Using Qualitative and Quantitative Approaches and Methods in Language "Testing and Assessment" Research: A Literature Review. Journal of Education and Learning, 6, 102-112. https://doi.org/10.5539/jel.v6n1p102

Randeree, K., \& Chaudhry, A. G. (2012). Leadership-Style, Satisfaction and Commitment: An Exploration in the United Arab Emirates' Construction Sector. Engineering, Construction and Architectural Management, 19, 61-85. https://doi.org/10.1108/09699981211192571

Šuklev, B., \& Debarliev, S. (2012). Strategic Planning Effectiveness Comparative Analysis of the Macedonian Context. Economic and Business Review, 14, 63-93.

Tiawo, A. S., \& Idunnu, F. O. (2010). Impact of Strategic Planning on Organisational Performance and Survival. Research Journal of Business Management, 4, 73-82.

Ukanwah, C. H., \& Ndaguba, E. A. (2015). The Place of Human Resource Management in Achieving Competitive Advantage in Nigerian Public Organisations under the Global Economy. Africa's Public Service Delivery \& Performance Review, 3, a94. https://doi.org/10.4102/apsdpr.v3i3.94

Vashdi, D. R., Vigoda-Gadot, E., \& Shlomi, D. (2012). Assessing Performance: The Impact of Organisational Climates and Politics on Public Schools' Performance. Public Administration, 91, 1-25. https://doi.org/10.1111/j.1467-9299.2011.01968.x

Yesil, S., \& Kaya, A. (2013). The Effect of Organisational Culture on Firm Financial Per- 
formance: Evidence from a Developing Country. Procedia-Social and Behavioural Sciences, 81, 428-437. https://doi.org/10.1016/j.sbspro.2013.06.455

Yilmaz, R., \& Bulut, F. M. (2015). An Article on the Effect of Human Resources Management on Organisational Performance. KNUV 2015, 2, 5-13. 